\title{
LA CONFRONTACIÓN DE DERECHOS EN LOS ESCRACHES
}

\author{
ALEXANDRE H. CATALÀ I BAS
}


SUMARIO

1. EL ESCRACHE COMO MODALIDAD DEL DERECHO DE MANIFESTACIÓN. 2 LIBERTAD DE EXPRESIÓN Y DERECHO DE MANIFESTACIÓN VS. DERECHOS DE LA PERSONALIDAD. 3. LIBERTAD DE EXPRESIÓN VS. DERECHO A DESEMPEÑAR UN CARGO PÚBLICO. 4. EL DEBATE EN SUS JUSTOS TÉRMINOS: ESCRACHE NO, MANIFESTACIÓN SÍ. 


\title{
LA CONFRONTACIÓN DE DERECHOS EN LOS ESCRACHES
}

\author{
ALEXANDRE H. CATALÀ I BAS \\ Profesor titular de Derecho Constitucional \\ Universitat de València
}

\section{EL ESCRACHE COMO MODALIDAD DEL DERECHO DE MANIFESTACIÓN}

El escrache es un fenómeno importado de Argentina que se ha puesto de moda en España. No es un fenómeno nuevo ni ningún tipo de nuevo derecho de los ciudadanos. Simplemente se trata de una modalidad de manifestación como mecanismo de presión sobre la clase política y surge en un momento de crisis como respuesta a la insatisfacción que genera en los ciudadanos el ser meros espectadores pasivos de decisiones que les afectan y que se adoptan por una clase política cooptada en el seno de los partidos políticos, cerrada y absolutamente disciplinada, lo que ha provocado, como señala Blanco Valdés un grave descrédito de la democracia representativa ${ }^{1}$.

Estos ciudadanos, muchos de ellos acuciados por graves problemas generados por la crisis económica que padecemos, desean que sus demandas no sólo sean escuchadas sino también asumidas por cargos públicos al tratarse de asuntos vitales y acuciantes aunque, en general, sectoriales, en el sentido de que no afectan a la totalidad de la población sino a parte de ella (desahucios, preferentes, etc.). Ello desemboca en un aumento de la presión sobre dichos cargos pues, convencidos quienes participan en estos actos de la inexistencia de otros meca-

1 Blanco Valdés, Roberto. «¿Escraches? No, gracias». Claves de la razón práctica, n 229 , 2013 , p. 61. 
nismos para influir en la agenda política, creen poder alcanzar su propósito personalizando la protesta y reduciendo la distancia física entre manifestantes y cargos en lugares al margen de la actividad pública de éstos últimos. En mi modesta opinión estas son las claves del escrache: a) demanda vital, acuciante y sectorial; b) personalización de la protesta en un cargo en concreto al que se le hace responsable o corresponsable de la situación; c) coincidencia espacial a poder ser o, al menos, reducción de la distancia física entre unos y otro en lugares en los que el cargo se comporta como particular; d) percepción de que esa mayor presión es la mejor manera de influir sobre él y puede hacerle cambiar de opinión asumiendo así sus reivindicaciones.

Todo ello nos lleva a un escenario en el que la libertad de expresión de los participantes en el escrache es ejercida con vehemencia y en el que los derechos de la personalidad de los cargos son objeto de una mayor presión o injerencia de las que soportan habitualmente.

\section{LIBERTAD DE EXPRESIÓN Y DERECHO DE MANIFESTACIÓN VS. DERECHOS DE LA PERSONALIDAD}

Como se señala en la STC 163/2006 una manifestación es «una asociación transitoria de personas, que opera a modo de técnica instrumental puesta al servicio del intercambio o exposición de ideas, la defensa de intereses o la publicidad de problemas y reivindicaciones, y cuyos elementos configuradores son el subjetivo (agrupación de personas), el temporal (duración transitoria), el finalista (licitud de la finalidad) y el real y objetivo (lugar de celebración)» (FJ 2). Y como tal, este derecho está íntimamente relacionado con la libertad ideológica y la libertad de expresión de manera que, como ha sido puesto de manifiesto por la jurisprudencia, juega un papel instrumental respecto de ellas. Así por ejemplo, el Tribunal Constitucional en su sentencia 85/1988 respecto al derecho de reunión señala que «es una manifestación colectiva de la libertad de expresión ejercida a través de una asociación transitoria». De esta relación con la libertad ideológica y la libertad de expresión deriva que este derecho desempeñe un papel similar a los dos citados en el normal funcionamiento del sistema democrático. Sin libertad de expresión, sin posibilidad de reunirse o manifestarse para exponer unas ideas o proyectos, o mostrar el acuerdo o desacuerdo con las decisiones adoptadas por las autoridades no hay ni pluralismo, ni tolerancia ni amplitud de criterios, sello distintivo, de acuerdo con el Tribunal de Estrasburgo, de una sociedad democrática. En la STEDH Güneri c. Turquía, de 12 de julio de 2005, ante la prohibición impuesta a un partido político de celebrar reuniones, el Tri- 
bunal de Estrasburgo recordó su jurisprudencia anterior en la que advierte que «la libertad de reunión y el derecho a expresar puntos de vista a través de ella, están entre los valores primordiales de una sociedad democrática. La esencia de la democracia es su capacidad de resolver los problemas por medio de debates abiertos. Las medidas restrictivas de naturaleza preventiva para suprimir la libertad de reunión y expresión, a menos que sean en casos de incitación a la violencia y rechazo de los principios democráticos, por más chocantes e inaceptables que puedan parecer a las autoridades algunos puntos de vista o palabras, o por más ilegítimas que puedan ser las exigencias, hacen un flaco favor a la democracia y a menudo la ponen en peligro» ${ }^{2}$.

La peculiaridad del escrache radica en que pretende una confrontación entre los participantes en la manifestación y los cargos públicos que han de adoptar una decisión que aquéllos no comparten; confrontación que se busca en el ámbito público-privado de dicho cargo, entendiendo por tal el espacio público en el que el cargo se desenvuelve al margen de sus funciones públicas, es decir, como un particular. Toda manifestación tiene un componente de presión sobre las personas que han de adoptar o han adoptado unas decisiones que no comparten los participantes en ésta. El escrache busca aumentar dicha presión haciendo coincidir en dicho lugar manifestantes y cargos públicos, tal como reconoce el Auto de la Audiencia Provincial de Madrid de 29 de enero de 2014 (caso escrache ante el domicilio de la Vicepresidenta del Gobierno).

Se confrontan aquí dos derechos. Por una parte, el derecho de manifestación, ligado especialmente a la libertad de expresión de las personas que se agrupan en los alrededores del domicilio del cargo representativo; por otra, el derecho a la intimidad y a la inviolabilidad del domicilio del político.

La libertad de expresión es uno de los pilares de la democracia. Una opinión pública libre sólo puede generarse a partir de un reconocimiento amplio de esta libertad, conditio sine qua non del pluralismo. Ello exige la posibilidad de que cualquier persona pueda expresarse libremente, pueda opinar o informar sin obstáculos sobre cualquier cuestión de interés general. Advertía Tocqueville que «la prensa es por excelencia el instrumento de la libertad» ${ }^{3}$. En este sentido Dalh considerará la libertad de expresión y la diversidad de fuentes de información como dos instituciones políticas básicas que debe reunir toda democracia. Las mismas «se requieren, en primer lugar, para que los ciudadanos puedan participar efectivamente en la vida política (...). Adquirir una comprensión ilustrada

2 Vide igualmente Stankov y Organización Macedonia Unida Ilinden c. Bulgaria, de 2 de enero de 2002 y Djavit An c. Turquía, de 20 de febrero de 2002.

3 Tocqueville, Alexis de, De la Democracia en América, Aguilar, tomo I, Edición 1989. 
de las acciones y políticas gubernamentales posibles también exige la libertad de expresión. (...) Finalmente, sin la libertad de expresión los ciudadanos enseguida acabarían perdiendo su capacidad de influir en la agenda de las decisiones políticas» ${ }^{4}$. Este derecho posibilita que el ciudadano tome conciencia de la existencia de todo un conjunto de derechos de los que es titular.

El TEDH ha repetido en incontables ocasiones que «en un sistema democrático, las acciones y omisiones del gobierno han de ser objeto de un atento control no sólo de los poderes legislativo y judicial sino también de la opinión pública» ${ }^{5}$. Como manifiesta Muñoz Machado, «no sólo no es pensable la democracia sin que exista la posibilidad de que los ciudadanos estén informados, sino que es imposible el pluralismo si esta información no es plena y libre» ${ }^{6}$. Favoreu le aplica el calificativo de «super liberté» ${ }^{7}$ y Cohen-Jonathan dice de ella que es «condición sine qua non de una verdadera democracia pluralista» ${ }^{8}$ Sin embargo, ello no justifica, como advierte Muñoz Machado, que nos encontremos ante una libertad supraconstitucional: «no hay ningún derecho constitucional que tenga características tan excelsas y absolutas. La libertad de comunicar y difundir informaciones y noticias tampoco» ${ }^{9}$. La libertad de expresión e información puede colisionar con otros derechos o bienes constitucionalmente dignos de protección. Dicho conflicto no se resuelve de forma automática en favor de aquél sino que, como han puesto de manifiesto TEDH y Tribunal Constitucional, habrá que decidir en cada caso, y teniendo presente todas las circunstancias obrantes en el mismo, cual es el derecho o bien constitucional que merece ser objeto de protección ${ }^{10}$.

4 Dahl, Robert, La democracia. Una guía para los ciudadanos, Taurus, 1999, p.112. Vide igualmente del mismo autor La Poliarquía. Participación y oposición, Tecnos, 1989, pp. 13 a 15.

5 STEDH Castells de 23 de abril de 1992, párf. 46. En el mismo sentido vide SsTEDH Incal de 10 de julio de 1998, párf. 54, Sürek (1) de 8 de julio de 1999, párf. 61, Sürek (3) de 8 de julio de 1999, párf. 37.

6 MuÑoz Machado, Santiago, Libertad de prensa y procesos por difamación, Ariel, 1987, p. 153.

7 Favoreu, Louis y Philip, Loïc, Les grandes décisions du Conseil constitucionnel, $6^{\mathrm{a}}$ edición, Sirey, 1991, pp. 609 y ss.

${ }^{8}$ Cohen-Jonathan, Gérard, «Article 10», La Convention européenne des Droits de l'Homme, PetTiti, Louis-Edmond (Director), Económica, 2a Edición, 1999, p. 366.

9 Muñoz Machado, Santiago, Libertad de prensa... op. cit. p. 12.

${ }^{10}$ La técnica de la ponderación o balancing ha sido criticada por MUÑOz MACHADO para quien «esta colisión no puede resolverse, sin más, como hace habitualmente nuestra jurisprudencia (...) con la apelación inmediata al balancing (...). Este método es inevitable cuando se trata de resolver una colisión entre derechos constitucionalmente situados en posición equiparable, pero no cuando se maneja un derecho colocado (...) en posición de preferencia. Como debe resolverse el conflicto en estos casos es verificando, antes que nada, si la libertad de información ha sobrepasado o no los límites de su ejercicio lícito o preferente; si se ha mantenido dentro del círculo en que puede 
Tanto el TEDH como el Tribunal Constitucional han destacado el carácter esencial que reviste la libertad de expresión e información en una sociedad democrática $^{11}$. Su trascendencia ya fue puesta de relieve por el TEDH en la sentencia Handyside de 7 de diciembre de 1976 al advertir que es uno de los pilares básicos sobre los que se asienta la sociedad democrática, añadiéndole, por tanto, una dimensión objetiva. Esta afirmación constituye, en palabras de Ryssdal «la filosofía de base de toda la jurisprudencia del Tribunal relativa al articulo 10 $\mathrm{CEDH}{ }^{12}$ y supone que «la libertad de expresión no es solamente una garantía contra las injerencias del Estado (derecho subjetivo) sino también un principio fundamental (objetivo) para la vida democrática» ${ }^{13}$.

Obligado es hacer referencia a la doctrina del carácter preferente de la libertad de expresión (doctrina abandonada ya de facto por el Tribunal Constitucional, que con el tiempo la ha sustituido por la doctrina del balancing). La libertad de expresión e información puede colisionar con otros derechos o bienes constitucionalmente dignos de protección. Dicho conflicto no se resuelve de forma automática en favor de aquél sino que, como han puesto de manifiesto TEDH y Tribunal Constitucional, habrá que decidir en cada caso, y teniendo presente todas las circunstancias obrantes en el mismo, cual es el derecho o bien constitucional que merece ser objeto de protección. En la STEDH Lingens de 8 de julio de 1986, el Tribunal de Estrasburgo advertirá que el carácter esencial de la libertad de expresión, no supone vaciar de contenido los derechos que entren

lícitamente sobreponerse a otros derechos en conflicto no habrá lugar a balanceamiento alguno, sino a la pura aplicación de una consecuencia de la configuración constitucional de una concreta libertad. Más allá de este ámbito de preferencia, o en los casos en que la información no resulte especialmente protegida, el contrapeso y la apreciación de las circunstancias del caso, será el método resolutorio del conflicto». MuÑOZ MACHADO, Santiago. Libertad de prensa... op cit. p. 150.

${ }^{11}$ En el mismo sentido el Comité de Derechos Humanos que afirma que «la libertad de información y la libertad de expresión son piezas angulares de toda sociedad libre y democrática» (Adimo M. Aduayom y otros c. Togo de 12 de julio de 1996). Igualmente puede verse del Tribunal de Justicia de las Comunidades Europeas el caso Vereinigte Familiapress de 26 de junio de 1997. Por último añadir que el Conseil Constitutionnel francés en su Decisión de 10-11 de octubre de 1984 la ha descrito en los siguientes términos: «es una libertad fundamental tanto más preciosa que su ejercicio es una de las garantías esenciales del respeto de otros derechos y libertades y de la soberanía nacional».

12 RyssDal, Rolv, «Jurisprudence de la Cour européenne des droits de l' homme sur la liberté d'expression garantie par la Convention européenne des droits de l'homme», Bulletin des Droits de l' Homme, 1997, vol. 7, p. 60.

13 Oetheimer, Mario, L'harmonisation de la liberté d' expression en Europe. A. Pedone, 2001, p. 60 . 
en conflicto con él aunque sí que los límites aplicables han de ser objeto de una interpretación estricta ${ }^{14}$.

En la STC 12/1982 de 31 de marzo (caso sociedad Antena 3, SA) el Alto Tribunal se decanta de forma expresa en favor de la tesis de la doble naturaleza de la libertad de expresión, como derecho subjetivo y como garantía institucional, dotándola de un cariz objetivo al calificarla de garantía de una institución fundamental como es la opinión pública, como ya hiciera el TEDH. En sentencias tales como las SsTC 171/1990, de 12 de noviembre [caso accidente de aviación (El País)] y 172/1990 de 12 de noviembre [caso accidente de aviación (Diario 16)], el Tribunal Constitucional fija el sentido del carácter preferencial de la libertad de expresión e información. En estas sentencias el Tribunal mantiene la tesis de que nos encontramos ante un derecho que goza de una superior jerarquía institucional, pero matiza a continuación con rotundidad que ello no supone configurar como absoluto el derecho en cuestión, que sólo goza de dicho carácter cuando se ejerce con la finalidad de garantizar la existencia de la opinión pública, perdiendo aquel carácter cuando se hace uso del mismo al margen de dicha finalidad. Esta referencia al carácter preferente de la libertad de expresión se mantendrá con posterioridad pero con mero sentido retórico. Como pone de manifiesto Gallego Anabitarte, el Tribunal Constitucional no hace referencia a dicha doctrina justamente en aquellos casos en que ha hecho una aplicación más restrictiva de la misma en los que «la garantía institucional o constitucional de la opinión pública hubiese sido un obstáculo en la argumentación» ${ }^{15}$. Ejemplos de ello son las SsTC 105/1983, de 23 de noviembre (caso Periodista Vinader), 51/1985, de 10 de abril (caso senador Castells), 105/1990, de 6 de junio (caso periodista José María García), 31/1994, de 31 de enero (caso de la televisión local por cable), o 270/1994, de 17 de octubre (caso rueda de prensa del guardia civil). En otros, más parece haberlo usado, como sigue diciendo este autor, más como argumento retórico ${ }^{16}$ o técnico nada convincente ${ }^{17}$ que como otra cosa. Ejemplos de ello son las SsTC 12/1982, de 31 de marzo (caso sociedad Antena 3, SA), 69/1989, de 20 de abril (caso de los comunicados de los policías que ostentaban cargos sindicales), 206/1990, de 17 de diciembre (caso de las televisiones y radios

14 En el mismo sentido vide por todas SsTEDH Barthold de 25 de marzo de 1985, Autronic AG de 22 de mayo de 1990, Oberchlick (1) de 23 de mayo de 1991, Sunday Times de 26 de noviembre de 1991, Informationsverein Lentia y otros contra Austria de 24 de noviembre de 1993 y Oberchlick (2) de 1 de julio de 1997 y Worm de 29 de agosto de 1997.

15 Gallego Anabitarte, Alfredo, Derechos fundamentales y garantías institucionales: análisis doctrinal y jurisprudencial, Cívitas, 1994, p. 220.

16 Idem. p. 187

17 Idem p. 220. 
locales), o 371/1993, de 13 de noviembre (caso del militar que criticó las pensiones a los militares de la República).

La STC 336/1993, de 15 de noviembre (caso de los insultos al alcalde Hormaechea) matiza el sentido que ha de darse al carácter preferencial del derecho, al rechazar incluso la terminología de la sentencia 172/1990, de 12 de noviembre (caso del accidente de aviación - Diario 16) que hablaba de «jerarquía institucional» para, en primer lugar, advertir que el carácter prevalente de que disfruta el derecho no significa una posición jerárquica superior, y, en segundo lugar, recordar que sólo goza de ese carácter cuando su ejercicio se desenvuelva dentro del ámbito constitucional señalado, que no es otro que el de garantizar una opinión pública libre. En la práctica se observa que la última jurisprudencia del Alto Tribunal, tal como señala Gallego Anabitarte, se ha inclinado por la «ponderación de los derechos en conflicto y deja en segundo plano el enfoque institucional» ${ }^{18}$.

El TEDH ha dejado claro desde un primer momento que el artículo 10 $\mathrm{CEDH}$ ampara tanto los juicios de valor o informaciones moderados, favorables o inocuos, como los que molestan, hieren o incomoden. En este sentido la sentencia Handyside de 7 de diciembre de 1976 señaló que: «al amparo del artículo 10.2 son válidas no sólo las informaciones o ideas que son favorablemente recibidas o consideradas como inofensivas o indiferentes, sino también aquellas que chocan, inquietan u ofenden al Estado o a una parte cualquiera de la población. Tales son las demandas del pluralismo, la tolerancia y el espíritu de apertura, sin las cuales no existe una «sociedad democrática» (párf. 49) ${ }^{19}$. El Tribunal Constitucional asumirá prontamente dicha tesis ${ }^{20}$. Ambos tribunales coincidirán igualmente en que la libertad de expresión ampara cierta dosis de exageración y provocación. A tenor de la STEDH Oberschlick de 23 de mayo de 1991 «... además del contenido de las ideas e informaciones expresadas, el artículo 10 protege la forma de expresarlas» ${ }^{21}$, de ahí que sea merecedor de protección, y

18 Idem pp. 188 y ss.

19 En el mismo sentido, y por todas, vide SsTEDH Lingens de 8 de julio de 1986, Müller de 24 de mayo de 1988, Thorgeir Thorgeirson 25 de junio de 1992, Oberchlick de 23 de mayo de 1991, Observer et Guardian de 26 de noviembre de 1991, Otto Preminger Institut de 20 de septiembre de 1994, Wingrove de 25 de noviembre de 1996, De Haes et Gijsels de 24 de febrero de 1997, y Oberschlick de 1 de julio de 1997.

20 Vide STC 62/1982, de 15 de noviembre.

21 En el mismo sentido, vide por todas SsTEDH Jersild de 23 de septiembre de 1994 (Párf. 31) y De Haes et Gijsels de 24 de febrero de 1997 (Párf. 48). 
según la STEDH Prager et Oberschlick de 26 de abril de 1995, «es posible el recurso a una cierta dosis de exageración, incluso de provocación» ${ }^{22}$.

Aunque propiamente no se trate de un escrache, consideramos interesante detenernos en la sentencia 31/2014, de 7 de julio de la Audiencia Nacional en el caso de la manifestación ante el Parlament de Catalunya pues aunque tuvo lugar en el espacio público propiamente dicho, se produjo un contacto directo entre manifestantes y cargos representativos. La sentencia parte de que existe una confrontación de derechos fundamentales: por una parte, considera la Audiencia Nacional que entra en juego la libertad de expresión de los manifestantes y, por otra, los derechos de los cargos representativos. La Audiencia hará uso de la doctrina primigenia del carácter preferente de la libertad de expresión y, en este sentido, concluirá que: «la libertad de expresión y el derecho de reunión y manifestación, íntimamente vinculados como cauces de la democracia participativa, gozan de una posición preferente en el orden constitucional, por lo que han de ser objeto de una especial protección y necesitan «de un amplio espacio exento de coacción, lo suficientemente generoso como para que pueda desenvolverse sin angostura; esto es, sin timidez ni temor» (STC 110/2000, Fj 5)». Olvida la Audiencia que si los manifestantes deseaban entrar en la distancia corta y entablar un debate o diálogo con los representantes políticos ese espacio sin coacción debe asegurarse a ambas partes y no solo a los que protestan. También ha de reconocerse en favor de los que son objeto de esa protesta de tal suerte que si estos se ven coaccionados no pueden actuar sin temor, como exige el Tribunal Constitucional. Si hablamos de diálogo, es decir de ejercicio de la libertad de expresión por ambas partes, éste debe plantearse en un escenario de absoluta normalidad sin coacciones o imposiciones. Si se priva de esa normalidad a alguna de las partes no es posible el diálogo. Como recuerda la STEDH Güneri, en una sociedad democrática se debe ofrecer una adecuada oportunidad de expresión de las ideas políticas que discutan el orden existente, siempre que su realización proponga por medios pacíficos, a través del ejercicio del derecho de reunión, así como por otros medios legales ${ }^{23}$.

Mientras que para el Tribunal Constitucional, STC 165/1987, de 27 de octubre, el carácter preferente de la libertad de expresión alcanza su máximo nivel cuando es ejercida por los profesionales de la información a través del vehículo institucionalizado de formación de la opinión pública, que son los medios

22 En el mismo sentido vide STEDH De Haes et Gijsels de 24 de febrero de 1997 (párf. 46).

23 Vide igualmente Stankov y Organización Macedonia Unida Ilinden c. Bulgaria, de 2 de enero de 2002 y Djavit An c. Turquía, de 20 de febrero de 2002. 
de comunicación ${ }^{24}$ y declina cuando su ejercicio se ha realizado por vías anormales e irregulares como hojas clandestinas, la Audiencia Nacional, ve con reticencia el ejercicio de esta libertad por los medios de comunicación en cuanto que controlan «los cauces de expresión y de acceso al espacio público», lo que hace que determinados sectores de la sociedad tengan una gran dificultad «para hacerse oír o para intervenir en el debate político y social» ${ }^{25}$. De ahí que refuerce su valor preferente en esos casos, y admita «cierto exceso en el ejercicio de las libertades de expresión o manifestación si se quiere dotar de un mínimo de eficacia a la protesta y a la crítica, como mecanismos de imprescindible contrapeso». El argumento de la Audiencia es más que discutible pues, a la vista de las imágenes de esa manifestación que los magistrados examinaron, parece estar justificando el recurso a cierta dosis de brusquedad física para hacer llegar sus reivindicaciones a los diputados y conseguir que cambien de opinión. Cierto es que tanto el TEDH como el Tribunal Constitucional amparan el exceso en la expresión pero ello hace referencia a la forma de expresarse, a las palabras utilizadas, siendo legítima cierta dosis de exageración o provocación sin caer en el insulto ${ }^{26}$. Sin embargo, en ningún caso se refieren al recurso a cierta dosis de violencia sobre

24 Asimismo vide Auto 136/1991, de 3 de junio. La STC 51/1989, de 22 de febrero (caso del capitán Pitarch) hablará de «medio institucionalizado de comunicación social» (FJ 6).

25 Reconoce el Tribunal Constitucional en la sentencia 163/2006, de 22 de mayo: «para muchos grupos sociales este derecho es en la práctica uno de los pocos medios de los que disponen para expresar públicamente sus ideas y reivindicaciones» A este argumento hace referencia la Audiencia Nacional en su sentencia de 31/2014. Tras afirmar que «para muchos grupos sociales el derecho de manifestación es, en la práctica, uno de los pocos medios de los que disponen para poder expresar públicamente sus ideas y reivindicaciones», lanza una andanada en toda la línea de flotación contra los grupos mediáticos y los medios de comunicación de titularidad pública a los que tacha de partidistas y de marginar las voces críticas: «Aparece la cuestión fundamental, en un orden constitucional democrático (...) de la posibilidad de las personas de hacerse oír, del acceso ciudadano al espacio público -delimitado y controlado por los medios de comunicación, en manos privadas, o, pocos, de titularidad estatal pero gestionados con criterios partidistas- y de la sistemática marginación de las voces críticas de minorías o de sectores sociales débiles. La realidad pone de manifiesto la invisibilidad de ciertas realidades dramáticas por la dificultad, cuando no, en muchos casos, de la más absoluta imposibilidad de quienes las sufren de acceder a la opinión pública para difundir y hacer llegar sus proclamas y opiniones». En definitiva: «El pluralismo como valor superior de nuestro ordenamiento jurídico obliga al Estado a garantizar la visibilidad de las distintas opiniones presentes en la sociedad, sobre todo de las voces silenciadas -mas cuando soportan mensajes sobre violaciones graves de derechos humanos básicos frente a las voces habitualmente sobrerrepresentadas», si se quiere un debate público «sin inhibiciones, de forma vigorosa y abierta».

26 Por todas SsTEDH Prager et Oberschlick de 26 de abril de 1995 y De Haes et Gijsels de 24 de febrero de 1997 y SSTC 51/1989, de 22 de febrero, 171/1990, de 12 de noviembre y 136/1994, de 9 de mayo. 
las personas para hacerse oír y menos para convencer a los legítimos representantes del pueblo y hacerles cambiar de opinión pues ello no es admisible en una sociedad democrática donde las ideas se defienden por métodos pacíficos. Por otra parte, la Audiencia da por sentado un hecho: que los que allí se manifestaban no tenían acceso a los medios de comunicación, afirmación más que discutible teniendo en cuenta que los responsables de plataformas contra los recortes, desahucios, etc., han gozado de minutos de antena ${ }^{27}$.

Señala la Audiencia que la protesta tenía dos formas de acción colectiva. Por un lado, la manifestación frente a la institución donde se iban a tomar determinadas decisiones, mediante la presencia de ciudadanos que querían hacer visible su indignación y oposición a las políticas de recorte del gasto social. De otro lado, la confrontación con los diputados, personalmente, para hacerles llegar el malestar ciudadano y su propia responsabilidad por el voto que iban a emitir. Considera la Audiencia, esta segunda fase como una modalidad actualizada de piquete, figura que «significa el establecimiento de un espacio de confrontación física y simbólica entre quienes disienten y las personas a las que se quiere hacer llegar el mensaje» y «propone una confrontación personal, física y moral, entre el objetor y el destinatario del requerimiento (el que decide, aquel al que se dirige de modo directo el mensaje de la protesta)». ¿Qué entiende la Audiencia por confrontación física? Una confrontación física es algo distinto a la confrontación verbal, argumental, intelectual o dialéctica.

A continuación la Audiencia introduce un argumento confuso y contradictorio. Considera que para llevar a cabo dicha confrontación en la que los miembros del piquete buscaban «dialogar con los representantes parlamentarios» es necesario establecer un perímetro para hacer compatible la acción de los pique-

27 Recordemos que el artículo 20.3. CE prevé un derecho de acceso de los grupos sociales y políticos significativos. En este sentido, la Decisión Comisión Europea de Derechos Humanos sobre el caso X y Asociación Z de 12 de julio de 1971 afirma que no puede reconocerse un derecho ilimitado de acceso a los medios, aunque, advertirá que en determinadas circunstancias una negativa a acceder a los medios puede suponer una vulneración del artículo 10 CEDH. Ello no obstante, la Comisión fue bastante restrictiva a la hora de reconocer este derecho (vide Decisiones de la ComEDH X c. Austria de 15 de febrero de 1965, X c. Alemania de 15 de diciembre de 1965 o X c. Alemania de 24 de julio 1970 y X c. Suecia de 7 de febrero de 1968). Por su parte, el Tribunal Constitucional en su en STC 63/1987, de 20 de mayo (caso Mesa para la Unidad de los Comunistas) afirmará que es legítima una regulación en el sentido de no permitir un acceso totalmente libre siempre y cuando se asegure el mismo a los grupos sociales y políticos significativos. Existe el peligro, puesto de manifiesto por la doctrina, de que la referencia a los grupos significativos pueda dificultar o impedir el acceso a las minorías. Un análisis de la regulación en España puede verse en Linde, Enrique; Vidal, José Ma , y Medina, Sara, Derecho Audiovisual, Colex, Madrid, $5^{a}$ edición en 2013 pags. 199-207. 
tes con la libertad de los diputados de acceder a la asamblea para ejercer sus funciones. Es decir, que tenían que dialogar a distancia, a gritos, en medio de la calle. El diálogo es incompatible con el establecimiento de perímetros de seguridad, máxime si se trata de un diálogo entre representantes de la sociedad pues así califica la Audiencia a los participantes en el piquete. Exigir un perímetro de seguridad supone reconocer implícitamente que esos supuestos representantes de la sociedad podían excederse en esa confrontación física. Para la Audiencia hay que confinar a éstos en un espacio físico de modo que los representantes políticos queden fuera de su alcance pues en caso contrario el diálogo se convierte en acoso. Un sinsentido de razonamiento. Termina la Audiencia recriminando a la autoridad gubernativa por no haber establecido dicho perímetro, y responsabilizándola de la situación, lo que es tanto como reconocer implícitamente que los miembros anónimos del piquete elevados por la Audiencia a la categoría de representantes de la sociedad no hicieron uso de la libertad de expresión, sino que se dedicaron a confrontarse físicamente con los diputados. Lo cierto es que al no haber ese perímetro de seguridad, pudo verse claramente que no se buscaba entablar un diálogo con los representantes políticos sino increparles y amenazarles con la intención de coaccionarles. Como señala el magistrado Fernando Grande-Marlaska en su voto particular «no puede hablarse de una confrontación ideológica, admitiendo la activa, cuando se escupe, se insulta, se acomete físicamente, se impide la libertad deambulatoria de distintos representantes de la soberanía popular, quienes deben repeler esas acciones, alguno de ellos, y teniendo que ser protegidos por agentes de la autoridad, como única posibilidad de recobrar el sentimiento de tranquilidad y acceso al Parlamento».

El cargo político, como personaje público, y tal como señaló el TEDH en el caso Lingens, de 8 de julio de 1986, ha de soportar una mayor injerencia en sus derechos de la personalidad que una persona privada, ya que «los límites de la crítica permitida son más amplios en relación con un político considerado como tal que cuando se trata de un mero particular, pues se expone inevitablemente a una fiscalización atenta de sus actos y gestos tanto por los periodistas como por la multitud de ciudadanos». La cuestión es si el político lo ha de ser las veinticuatro horas del día y en todo lugar y momento, lo que permita a los ciudadanos hacerles llegar sus opiniones y ejercer esa presión o llegar a esa «confrontación física» sin tener en cuenta las variables espacio-tiempo; o bien si el político no lo es a jornada completa y, por lo tanto, fuera del espacio y del tiempo en los que ejerce funciones públicas merece ser tratado lo más próximo posible a una persona privada por lo que en ese contexto privado, el resto de ciudadanos han de abstenerse de tales actitudes. Para contestar a esta cuestión hay que acudir, en 
primer lugar, a la sentencia Lingens y ver qué nos está diciendo el TEDH cuando habla que los derechos de la personalidad de un político han de soportar un mayor grado de injerencia cuando es considerado como tal ${ }^{28}$. La respuesta es clara: en relación con el ejercicio de sus funciones públicas. Distingue así el Tribunal entre el político cuando actúa como tal y el político que actúa al margen de sus funciones públicas. Se desprende de la sentencia que en este segundo caso, el político no ha de soportar ese plus de injerencia en sus derechos. Indudablemente ningún personaje público, ni siquiera los de primera magnitud, por utilizar una categorización del Tribunal de Estrasburgo ${ }^{29}$, puede estar bajo los focos de la opinión pública veinticuatro horas al día, siete días a la semana y doce meses del año, y en cualquier lugar. Ello supondría una disminución de su vida privada y del disfrute de su domicilio, como emanación espacial de la primera, más allá de lo que razonablemente se deriva del ejercicio de un cargo público. A nadie se le puede exigir tal sacrificio.

Aceptemos que, como dice el TEDH y el TC, el político cuando actúa como tal ha de soportar un mayor grado de injerencias en su vida privada que un particular, pues por su condición pública suscita un mayor interés en la opinión pública. Ello no obstante, esta doctrina parte de la concepción tradicional de la vida privada como derecho a mantener fuera del conocimiento de terceros determinadas facetas privadas de una persona. Pero el derecho a la vida privada tiene un gran número de facetas que van más allá de la salvaguarda de datos o hechos privados de las personas. Ya en el caso Niemietz de 16 de diciembre de 1992, el TEDH advirtió que no apreciaba «ni posible ni necesario definir de manera exhaustiva» lo que es vida privada. Al respecto señala Martínez Sospedra que: «nuestra jurisprudencia constitucional viene eludiendo cuidadosamente el establecer si no una definición, sí al menos una doctrina general, clara y razonablemente precisa acerca de qué deba entenderse por tal. En ello el TC no es una excepción, sigue una pauta generalizada (...) justificada normalmente por razón de la extrema dificultad de precisar cuál pueda ser al menos el núcleo esencial (el core) de dicho concepto, no otra cosa viene a hacer el TEDH, que sigue la misma o parecida línea de conducta a la hora de interpretar el precepto correlativo del

28 Párf. 42. Versión francesa: «Partant, les limites de la critique admissible sont plus larges à l'égard d'un homme politique, visé en cette qualité, que d'un simple particulier». Versión inglesa: «The limits of acceptable criticism are accordingly wider as regards a politician as such than as regards a private individual». Vide igualmente STEDH Hannover c. Alemania de 24 de junio de 2004.

29 STEDH Hannover c. Alemania de 24 de junio de 2004. 
Convenio: el art. $8 \mathrm{CEDH}$, si acaso el TC es más preciso que el TEDH.» ${ }^{30}$. Ello le ha permitido conocer al TEDH de un gran número de casos que desbordan la concepción tradicional del derecho ${ }^{31}$.

Los derechos a la intimidad y al domicilio han sido encuadrados como derechos de primera generación de los que, en principio, generan hacia el Estado obligaciones negativas o de no injerencia. Los poderes públicos y los particulares han de abstenerse de penetrar en ese ámbito. Pero esta concepción hace tiempo que ha sido superada. También los derechos de primera generación engendran obligaciones positivas hacia el Estado, ligado ello a la teoría de la eficacia horizontal de los derechos (Drittwirkung) ${ }^{32}$. Así, en relación con el derecho a la vida privada y familiar, el TEDH señaló en su sentencia Marckx de 13 de junio de 1979 que: «al proclamar en el párrafo primero el respeto a la

30 Martínez Sospedra, Manuel. «Sobre la intimidad. Derecho a la intimidad, vida privada y privacy. El artículo $8 \mathrm{CE}$ in principio en la jurisprudencia del Tribunal Constitucional», en la obra colectiva Sobre la intimidad, Fundación Universitaria San Pablo C. E. U., 1996, p. 123.

${ }^{31}$ El TEDH, evita dar definiciones acabadas de los distintos derechos para eludir la correspondiente rigidez. Rompe así los límites ratione materiae. Existen unos calculados márgenes de indefinición que, en la práctica, se traducen en una especie de vis attractiva de los derechos del Convenio en el sentido de recoger en su seno aspectos que quedarían extramuros de los mismos si se partiese de definiciones estrictas. Así, el TEDH ha incluido bajo el paraguas de la vida privada circunstancias tan dispares como la integridad física o moral (STEDH X y C. contra los Países Bajos de 26 de marzo de 1985); el honor (STEDH Maekt Intern Verlag GmbH y Klaus Beermann, de 20 de noviembre de 1989); la propia imagen (SSTEDH Hannover c. Alemania de 24 de junio de 2004 y de de 7 de febrero de 2012); la vida sexual (SsTEDH X y C. contra los Países Bajos de 26 de marzo de 1985 y Dudgeon de 22 de octubre de 1981); la libre disposición del propio cuerpo en la que cabe incluir la transexualidad (STEDH Rees de 17 de octubre de 1986), la interrupción voluntaria del embarazo ( Informes de la Comisión casos Patton de 13 de mayo de 1980 y Brüggemann y Scheuten de 12 de julio de 1987) o las conductas sadomasoquistas (STEDH Laskey, Jaggard y Brown de 19 de febrero de 1997); los datos personales (SsTEDH Laender de 26 de marzo de 1987 y Gaskin de 7 de julio de 1989) incluidos los de tipo económico (STEDH Fressoz y Roire de 21 de enero de 1999); el cambio de apellidos (STEDH Burghartz de 22 de febrero de 1994 y Stjerna de 25 de noviembre de 1994); las relaciones familiares (SsTEDH Moustaquim de 18 de febrero de 1991, Beljoudi de 26 de marzo de 1992 o Nasri de 13 de julio de 1995); la filiación (STEDH Marckx de 13 de junio de 1979); los derechos-deberes de cuidado y custodia de los hijos ( STEDH Marckx de 13 de junio de 1979); la calidad de vida o derecho a un medio ambiente adecuado (SsTEDH López Ostra de 23 de noviembre de 1994, Guerra de 19 de febrero de 1998 y Hatton de 2 de octubre de 2001).

32 SUDRE, Fréderic, La Convention européenne des droits de l'homme, PUF, Collection que sais-je?, $n^{\circ}$ 2513, París, 1992. En el mismo sentido vid. Carrillo Salcedo, Juan Antonio, «Protección de Derechos humanos en el Consejo de Europa: hacia una superación de la dualidad entre los derechos civiles y políticos y derechos económicos y sociales», Revista de Instituciones Europeas, vol. 18, núm. 2, 1991, pp. 431-454. 
vida familiar de cada uno, el artículo 8 supone en primer lugar que el Estado no puede interferir en el ejercicio de ese derecho más que de acuerdo con los términos que estrictamente establece el párrafo segundo del mismo artículo (...), el objeto de tal artículo es esencialmente la protección del individuo frente a injerencias arbitrarias de los poderes públicos (...). No obstante, el Estado no sólo debe abstenerse de tales interferencias, sino que, junto a tal obligación de carácter negativo, existen asimismo obligaciones positivas derivadas del respeto efectivo a la vida familiar». Obligado es acudir a la STEDH López Ostra c. España, de 24 de noviembre de 1994 pues es un hito en el reconocimiento de obligaciones positivas en relación con ellos ${ }^{33}$. En esta sentencia, el Tribunal concluyó que estos derechos incluían una faceta hasta entonces no comprendida y que había sido negada por nuestro Tribunal Constitucional ${ }^{34}$ : el derecho a disfrutar de una calidad de vida digna que debía ser asegurada por los poderes públicos mediante obligaciones positivas. Ya no se trataba simplemente de asegurar un espacio libre de injerencias de terceros, sino de que el Estado ha de asegurar que esa vida privada y familiar y ese domicilio sean disfrutados en condiciones dignas. Quien es perturbado en ese disfrute ve su derecho vulnerado y si el Estado permite esa perturbación es responsable por ello. Esta faceta del derecho incluye el derecho a ser dejado en paz, a no ser molestado, a no ser objeto de atención por parte de terceros cuando actúa al margen de su faceta pública. La consagración de esta doctrina la tenemos en la STEDH Hannover

33 Critican algunos autores hacer uso de esta sentencia cuando se habla de escraches: PRESNO Linera, Miguel Ángel, «Los escraches», El Cronista del Estado social y democrático de Derecho, $\mathrm{n}^{\circ} 37$, 2013, p. 79; y MARTín PALlín, José Antonio, «El «escrache»: ¿un delito o una forma de ejercitar derechos fundamentales?, Diario la Ley, no 8090, 24 de mayo de 2013, p. 5. No compartimos esta crítica. Es cierto que el caso López Ostra hace referencia a malos olores pero se ha aplicado por los tribunales españoles para casos de ruidos provocados en la calle o en locales cercanos a la vivienda del afectado. Además esta sentencia del Tribunal de Estrasburgo no es la única. Así tenemos, por ejemplo las Ss'TEDH Guerra de 19 de febrero de 1998, Hatton de 2 de octubre de 2001 sobre ruidos. Y, en España, entre otras muchas citar STC 119/2001 de 8 de junio, STSJC 1001/1999, de 21 de octubre y STSJCV 235/1997, de 7 de marzo, 293/1998, de 23 de marzo y 952/1999, de 1 de junio. Esta jurisprudencia es de especial trascendencia pues considera que afecta a la vida privada y familiar y al domicilio el estar sometido a unas condiciones externas que afecten a la calidad de vida, sosiego, tranquilidad o descanso de una persona por lo que entendemos que es de plena aplicación aquí.

34 Por Auto de 26 de febrero de 1990 el Tribunal Constitucional inadmitió el recurso de amparo de la demandante por defecto manifiesto de fundamento. Advertir que la jurisprudencia del TEDH contenida en el caso López Ostra fue asumida por el Tribunal constitucional. Vide en este sentido la STC 119/2001 de 8 de junio en la que el Tribunal admite que en determinados casos de especial gravedad, ciertos daños ambientales pueden afectar, además de a los derechos a la intimidad y a la inviolabilidad del domicilio, al derecho a la integridad física y moral. 
c. Alemania de 24 de junio de 2004, y se ha ido consolidando en otros casos ante el Tribunal de Estrasburgo, en relación con un fenómeno que no es el aquí analizado pero con el que guarda cierta similitud: la gran atención mediática que sufren determinados personajes públicos en todo momento y lugar, que genera situaciones de verdadero acoso y desasosiego con quebranto de la integridad física y psíquica, tal como reconoce el propio TEDH, derechos que incluye en el derecho a la vida privada. Cuando se habla de integridad psíquica y física no cabe entrar en graduaciones, como en el caso del derecho a la vida privada entendida en su concepción tradicional. Todas las personas tienen el mismo derecho a la integridad sin posibilidad de establecer graduaciones por el puesto que ocupen.

Algunas de las líneas maestras de esta doctrina pueden ser de aplicación al fenómeno aquí estudiado. Partimos de la confrontación de dos derechos que también aparecen enfrentados en los escraches: la libertad de expresión y el derecho a la intimidad. Hay un elemento fáctico que coincide: la situación de presión o atención que sufre el personaje público. Existe una coincidencia del elemento real y objetivo: esa situación se da en el espacio público, normalmente en los alrededores del domicilio de aquél. A ello hay que sumar la coincidencia en otro elemento que podríamos llamar funcional: en esos momentos el personaje público no está ejerciendo sus funciones públicas. Sin embargo, el elemento finalista difiere en ambos casos: en el caso de los paparazzi y la prensa del cuore no se trata de dar a conocer cuestiones de interés general o público, sino de mero interés del público, mientras que en los escraches sí se da ese interés público. Para el Tribunal de Estrasburgo, seguido en este punto ya por el Tribunal Constitucional alemán ${ }^{35}$, el personaje público tiene derecho a no ser objeto de atención de los medios cuando no está desempeñando sus funciones públicas. Si aplicamos a los escraches esta doctrina cabría diferenciar entre si la manifestación se da en un lugar donde el cargo está en el ejercicio de sus funciones (lugar de trabajo, un acto público, etc.) o se da en un ámbito en el que no está en dicho ejercicio (su domicilio, un restaurante, un hotel en vacaciones...).

El lugar donde se realiza una manifestación es elemento a tener en cuenta, pues, como se señala en la STC 66/1995, de 8 de mayo, «este elemento objetivo configurador del derecho de reunión tiene en la práctica un relieve fundamental ya que está íntimamente relacionado con el objetivo de publicidad de las opiniones y reivindicaciones perseguido por los promotores por lo que ese emplazamiento condiciona el efectivo ejercicio del derecho. En realidad, en ciertos tipos de concentraciones el lugar de celebración es para los organizadores la condición necesaria para poder ejercer su derecho de reunión en lugares de trán-

35 Vide su sentencia de 26 de febrero de 2008. 
sito público, puesto que del espacio físico en el que se desenvuelve la reunión depende que el mensaje que se quiere transmitir llegue directamente a sus destinatarios principales». De ahí que, como sigue señalando el Alto Tribunal, «la posibilidad de realizar la concentración en un lugar próximo a la sede de las entidades afectadas y en un horario de trabajo se convierte, en estos casos, en factores determinantes a la hora de ejercer el derecho de reunión». Efectivamente, el espacio público es también lugar de participación. Si el ciudadano quiere hacer oír sus reivindicaciones el lugar donde se manifiesta cobra su importancia, de ahí que no sea posible desterrar la manifestación fuera del foro, al extrarradio. Posiblemente construir un manifestódromo, como se pretendía por el Ayuntamiento de Madrid y obligar a la gente a manifestarse en él iría en contra del derecho de reunión y manifestación.

Un escrache aisladamente considerado y que haya discurrido por cauces normales provoca unas «indudables inconveniencias» tal como reconoce el Auto de la Audiencia Provincial de Madrid, Sección 16a , de 29 de enero de 2014, que desestima el recurso interpuesto contra el archivo de diligencias del auto del juzgado $n^{\circ} 4$ de Madrid citado, que en sí mismas no revisten mayor trascendencia. En el propio Auto la Audiencia Provincial atribuye escasa trascendencia a dichas inconveniencias habida cuenta del «escaso tiempo en que se produjo la referida circunstancia y por la presencia policial que atempera la inquietud o intranquilidad». El problema surge cuando el escrache se repite con cierta frecuencia o excede el grado de intensidad permitido. Incluso aceptando que el cargo público ha de soportar una disminución de su derecho a la integridad, ¿qué sucede con sus familiares? Imponerles esta carga no parece razonable. Hemos señalado al principio que, por regla general, los intereses de los autores de un escrache son vitales, acuciantes pero sectoriales. Tan acuciante es el tema de los desahucios, como el de las preferentes, como la dependencia o como la supresión de ayudas a determinados colectivos. Todos tienen razones para realizar un escrache. Si se permite a unos ha de permitírseles a otros ¿Dónde poner el límite? Para ello habría que analizar el objeto de la protesta y el número de escraches ya sufridos por el representante político. La Autoridad gubernativa y los tribunales tendrían que analizar la trascendencia y vitalidad del objeto de la protesta y ver si el representante ya había o no cubierto el cupo (¿semanal? ¿quincenal?, ¿mensual?) Se me antoja labor casi imposible. Y aquí es interesante, como curiosidad, traer a colación el Auto del Juzgado de Instrucción n ${ }^{\circ} 1$ de Torrelavega, de 20 de abril de 2013 en el que se acuerda el sobreseimiento libre en relación con un escrache llevado a cabo ante el domicilio del alcalde por miembros de la plataforma Stop desahucios. Podemos compartir sin ninguna dificultad que no hubo hechos que pudieran dar lugar a una sanción penal o administrativa pues las cosas 
trascurrieron dentro de la normalidad. Lo que llama la atención es que se hiciera ante el domicilio del alcalde. ¿Qué competencias tiene el alcalde en materia de desahucios? Es decir, un político tendría que soportar escraches motivados por actuaciones propias y también por cuestiones sobre las que no tiene competencias. Lo justifica el juez en que «es servidumbre de todo cargo político, en un régimen democrático (art. 1.1. CE) soportar pacientemente las molestias que pueden causar este tipo de actos» haciendo una referencia genérica y rápida a la jurisprudencia del Tribunal Constitucional y del Tribunal Europeo de Derechos Humanos. A nadie se le puede exigir tal sacrificio y en este sentido no comparto la afirmación contenida en la STC 172/1990, de 12 de noviembre en el sentido de que todos los personajes públicos «aceptan voluntariamente el riesgo de que sus derechos subjetivos de personalidad resulten afectados por críticas, opiniones o revelaciones adversas». Esta afirmación ha de ser matizada en el sentido de que algunos lo aceptarán voluntariamente, incluso lo buscarán, y otros se verán abocados a ello por las circunstancias, independientemente de su voluntad. Es decir, la persona que se dedica al mundo del llamado papel cuché puede desear que se hable de su intimidad o que se acuda a la puerta de su domicilio a ver qué hace o dice pero la persona que es nombrada diputado o diputada lo que voluntariamente hace es presentarse y aceptar, en su caso, el cargo y de ahí derivará como consecuencia necesaria un mayor grado de injerencia en sus derechos de la personalidad, pero ello se dará independientemente de la voluntad del cargo. Pero la jurisprudencia del TEDH sí diferencia el sitio en el que el personaje público es presionado por parte del público de tal suerte que si es un lugar en el que actúa y se comporta como particular sus derechos a la personalidad han de soportar un grado de injerencia similar a la de una persona particular. En este sentido se manifiesta el Tribunal Superior de Justicia del País Vasco en sentencias

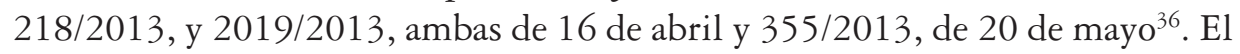
Tribunal considera que la manifestación ante el domicilio de una Consejera del gobierno vasco constituye una perturbación desproporcionada en su derecho a la intimidad personal y familiar. Considera la Sala que no es necesaria «puesto que para que el mensaje que se pretende transmitir llegue a un representante político existen lugares alternativos, distintos de su domicilio particular, e igualmente operativos para que alcance repercusión en la opinión pública, en los medios de comunicación, y a los representantes políticos, a los que más directamente se dirige» y resulta injustificado «cuando se programa el domicilio particular, como

36 Todas ellas duramente criticadas por Alonso Rimo, Alberto. «Escraches, Derechos de Reunión y criminalización de la protesta social», Teoría y derecho: revista de pensamiento jurídico, $\mathrm{n}^{\circ} 14,2013$, pp. 144-165. 
lugar de concentración, con la finalidad de presionar la voluntad del representante político, precisamente mediante la injerencia en su ámbito más íntimo y personal. Lo que se instrumentaliza como elemento de presión es la injerencia en la vida privada y personal del representante político» ${ }^{37}$. Advierte Barceló que el juzgador «tendrá que considerar si el lugar de celebración escogido es para los organizadores la condición necesaria para poder ejercer su derecho de reunión, es decir, para asegurar que el espacio físico en el que se desenvuelve la reunión es el adecuado para que el mensaje que se quiere transmitir llegue directamente a su destinatario principal» ${ }^{38}$. Si eso es así y ponderando los derechos en conflicto en caso de existir otro lugar que no provoque esa injerencia en los derechos de los cargos representativos y que asegure igualmente dicho objetivo: por ejemplo, la sede del partido político o de la institución donde el cargo desempeña sus funciones habrá que decantarse por esta opción.

Todo lo anterior nos lleva al siguiente punto: Si el objeto de esa mayor presión es influir en su toma de decisiones, entra en juego el derecho a desempeñar con normalidad las funciones públicas.

\section{LIBERTAD DE EXPRESIÓN VS. DERECHO A DESEMPEÑAR UN CARGO PÚBLICO}

De acuerdo con el Tribunal Constitucional, sentencia 5/1983, el derecho a ser elegido para cargos públicos contiene el derecho a permanecer en ellos. El sufragio pasivo sólo puede tener sentido jurídico como correlato del sufragio activo de los electores de tal suerte que, STC 10/1983, la vulneración que resulta del hecho de privar al representante de su función afecta, sin embargo, a todos simultáneamente y es también una vulneración del derecho del representado a ejercer la función que le es propia, derecho sin el que, como es obvio, se vería vaciado de contenido el de los representados. Y es que, STC 161/1988, de 20 de septiembre de 1988, el núm. 2 del artículo 23 CE garantiza «no sólo el acceso igualitario a las funciones y cargos públicos, sino también que los que hayan accedido a los mismos se mantengan en ellos sin perturbaciones ilegítimas y los desempeñen de conformidad con lo que la ley disponga» (FJ 6). El estatuto del parlamentario, especialmente las prerrogativas parlamentarias, protege al parlamentario de esas agresiones ilegítimas. Como dirá García Roca, ello deriva de la

37 Vide igualmente sentencia del Tribunal Superior de Aragón 274/2003, de 14 de mayo.

38 Barceló i Serramalera, Mercè. «Las libertades de expresión y de reunión en la Constitución española: breve apunte sobre los «escraches» como punto de confluencia entre ambas libertades», Espaço Jurídico, vol. 14, 2013, p. 52. 
necesidad de preservar el verdadero fundamento del artículo 23.2. C. E. que no es otro que asegurar el derecho de los ciudadanos a participar en los asuntos públicos a través de los representantes (artículo 23.1 CE). Con esta concepción del derecho fundamental resulta fortalecido también el vínculo jurídico directo entre electores y elegidos o entre ambas clases de sufragio ${ }^{39}$. Esta doctrina está pensada para proteger al cargo representativo de la presión o control del partido político o del grupo parlamentario o municipal e intentar salvaguardar la relación elector-elegido maltrecha por tal fenómeno. La paradoja del caso es que con los escraches, la idea de que el cargo ha de poder desempeñar su función fuera de presiones externas ha de aplicarse a la relación que justamente pretende proteger: la relación elector-elegido.

Un escrache, como se ha señalado, intenta aumentar la presión sobre el cargo político en vista a las decisiones adoptadas o que se vayan a adoptar en un futuro. Indudablemente si alcanzaran determinada intensidad, esos actos pueden incurrir en diferentes ilícitos penales (por ejemplo: delito o falta de amenazas de los artículos 171 CP o 620 CP o delito de coacciones del artículo 172 CP). Desembocaríamos así en las perturbaciones ilegítimas de las que habla el Tribunal Constitucional. A la luz del Auto del juzgado de Instrucción n 4 de Madrid, de diez de mayo de 2013, por el que se decretó el archivo de las actuaciones en el caso del escrache contra la Vicepresidenta del Gobierno, el juez deja claro que el derecho de reunión no ampara el insulto, la amenaza o la coacción y el uso de la fuerza (vg. golpear la puerta del domicilio, realizar pintadas, intentar superar el control policial que rodeaba la vivienda, lanzar objetos, acometer a los agentes policiales, formar barricadas, causar daño al mobiliario urbano, etc.), argumentando que «en tales casos estaríamos ante un claro abuso del derecho fundamental que encontraría su tipificación en el Código penal (artículos 620.2, 634, 169, 172 y 513 . CP y otros)».

Imposibilitar o dificultar el ejercicio de este derecho supone una vulneración del derecho de todos los ciudadanos a participar en los asuntos públicos (artículo 23.2. CE). Es legítimo que una manifestación sea reivindicativa y crítica con las decisiones adoptadas o a adoptar por determinados cargos públicos y que los manifestantes les hagan llegar a través de ella su descontento pero no hay que olvidar que éstos se representan a sí mismos no al resto de la sociedad, como parece dar a entender la Audiencia Nacional que en su sentencia 31/2014 (caso Escrache ante el Parlament de Catalunya) considera que los participantes en el piquete que se «confrontaba con los diputados del Parlament de Catalunya» «se erigían en portavoces de un sector de la sociedad». Ante ello cabe preguntarse

39 García Roca, Javier, Cargos públicos representativos, Aranzadi, 1999, pp. 118-119. 
quién y a través de qué mecanismos les había sido atribuida tal facultad. El argumento de la Audiencia es del todo erróneo y nos llevaría a reconocer la existencia de una confrontación entre unos representantes de parte de la sociedad anónimos, sin poder esgrimir título habilitante de esa representación y unos representantes con nombres y apellidos de esa misma sociedad, elegidos unos meses antes en las urnas. Por otra parte, el cargo no está sujeto a mandato imperativo. Si la presión fuera tan fuerte que el cargo público se sintiera coaccionado y variara su voluntad política nos encontraríamos con una vulneración del derecho de los ciudadanos a participar en los asuntos públicos.

Puede ser cierto lo que dice Sartori en el sentido de que «cuanto más se sometan [los representantes] a las exigencias de sus electores más afectada se ve la labor del Gobierno por la prevalencia de los intereses localistas sobre los generales» ${ }^{40}$; ello no obstante, hay que arbitrar fórmulas de participación política que permitan a los electores relacionarse con los cargos representativos. Como advierte Martin Pallín, «en otros países con mayor solera democrática el ciudadano puede satisfacer sus demandas acudiendo a las oficinas donde los parlamentarios atienden sus quejas. Si esta práctica se generalizase en nuestro país los escraches carecerían de sentido» ${ }^{41}$.

\section{EL DEBATE EN SUS JUSTOS TÉRMINOS: ESCRACHE NO, MANIFESTACIÓN SÍ.}

Los partidarios del escrache ven en su prohibición una violación del derecho de reunión y manifestación a partir de un razonamiento que considero no acertado: No se permite el escrache ergo se vulnera automáticamente el derecho de reunión y manifestación.

Sin embargo, considero que esto es una simplificación de los términos en que hay que plantear la cuestión. Una manifestación es una reunión de personas en el espacio público con el objeto de exponer sus ideas o reivindicaciones y como

40 SARTORI, GIOVANNi «En defensa de la representación política», Claves de razón práctica, núm. 91, 1999.

41 Martín Pallín, José Antonio, «El «escrache»..., op. cit. p. 2. Hemos señalado al inicio de este trabajo que el escrache se caracterizaba, entre otros elementos, por la convicción de los manifestantes de no poder acceder a los cargos políticos. También lo recuerda Presno Linera, Miguel Ángel, «Los escraches»..., op. cit. p. 74. cuando recoge fragmentos de la carta abierta a los diputados de 23 de febrero de 2013 de la Plataforma de Afectados por la hipoteca, en la que solicitaban reunirse con ellos. Es cierto que la falta de sensibilidad de nuestros políticos, a quienes no se les pide que acepten dichas reivindicaciones pero sí al menos que las escuchen de viva voz, ha sido uno de los detonantes de este tipo de actuaciones. 
hemos dicho, de acuerdo con el Tribunal Constitucional sus elementos configuradores son el subjetivo (agrupación de personas), el temporal (duración transitoria), el finalista (licitud de la finalidad) y el real y objetivo (lugar de celebración)». De estos, el único que se cuestiona en los escraches es el último: el lugar de celebración. Los manifestantes no pueden esperar entablar un diálogo con el cargo en cuestión ya que, como exige la Audiencia Nacional habrá que establecer un perímetro de seguridad. Por lo tanto, queda descartado que con el escrache se vaya a conseguir esa relación directa. Lo que sí se conseguirá es aumentar la presión en ese espacio público-privado; es decir, someter al cargo político a una serie de molestias con el objeto de conseguir mayor repercusión mediática. Indudablemente, no es lo mismo gritar a un político a cien metros del lugar de trabajo que aporrear la puerta de su domicilio. Se pretende alcanzar mayor repercusión mediática y, en teoría, que el político preste mayor atención a costa de una mayor injerencia en sus derechos de la personalidad y en el de sus familiares incluso con el peligro de que la reivindicación quede sofocada por el acto reivindicativo (nos acordamos de que aporrearon una puerta pero ¿y de la reivindicación que estaba detrás de estos actos?). Sin embargo, se puede alcanzar una repercusión y atención similar manifestándose en el espacio público propiamente dicho; por ejemplo, ante la institución en la que el cargo desempeña sus funciones o ante la sede de su partido sin que sufran los derechos de las personas antes mencionadas. ¿De quién depende lograr esa mayor o menor repercusión? En parte de los propios manifestantes: mensaje, número de participantes en la manifestación, etc. Pero especialmente de los propios cargos políticos y de los medios de comunicación. En relación a los primeros ya hemos dicho que la falta de sensibilidad al no reunirse al menos con los representantes de estos colectivos ha sido uno de los detonantes de este tipo de actuaciones. En cuanto a los medios, son los que deciden qué sale y qué no sale en pantalla, en las ondas, en papel... Y muchas veces, desgraciadamente, los medios prestan mayor importancia a la anécdota de la imagen (aporrear la puerta) que a la reivindicación en sí. Lo trascendente no es que se manifiesten ante la casa de un cargo político, lo importante es que unas personas se manifiestan para evitar que las desahucien de sus casas. Eso sería suficiente para ser recibidos por los cargos políticos y disfrutar de minutos de antena sin necesidad de recurrir a este tipo de actos. Eso dejaría sin sentido la realización de los escraches y sólo así se aseguraría que en el espacio en el que el cargo público se comporta como una persona privada, la injerencia estuviera sometida a mayores controles, ya que, aunque político, podría esperar legítimamente no ser objeto de una manifestación en los alrededores de su domicilio y disfrutar del derecho al descanso y a un momento de distensión o de expansión, a salvo de las presiones de la vida profesional o cotidiana. 
Todo lo anterior nos lleva a concluir que un escrache que se haya producido en condiciones normales no es ni mucho menos algo que pueda ser considerado una conducta delictiva y que la solución, aun reconociendo que en dicho escrache el político se ve sometido a una injerencia injusta en sus derechos de la personalidad pues en esos momentos se comporta como un particular más, no está en criminalizarlo (el Derecho no lo puede todo y menos el Derecho penal) sino en cambiar determinados hábitos y costumbres especialmente de políticos y medios de comunicación. De hacerlo, los manifestantes no tendrían la necesidad de recurrir a este tipo de actos. Sin embargo, son dos las cuestiones que se suscitan: ¿están los primeros dispuestos a cambiar de actitud?; ¿les interesa a los segundos, desde el punto de vista de la audiencia, que no se produzcan este tipo de actos?

Title:

THE CONFRONTATION BETWEEN RIGHTS AND THE PRACTICE OF«ESCRACHES»

\section{Summary:}

1. The escrache as a modality of the right to demonstrate. 2. Freedom of expression and right to demonstrate vs. personality rights. 3. Freedom of expression vs. right to exercise public office. 4. The debate on fair terms: «No» to escrache, «Yes» to demonstration.

\section{Resumen:}

La reciente práctica de los escraches en España, en el contexto de la crisis económica, ha planteado un complejo debate en torno a la confrontación entre derechos fundamentales. En efecto, de un lado, debe tenerse en cuenta el derecho al libre ejercicio de un cargo público y los derechos de la personalidad (integridad, vida privada y familiar o disfrute pacífico del domicilio) cuando no se actúa en calidad de representante público. De otro lado, debe tomarse en consideración el ejercicio de otros derechos fundamentales (expresión, manifestación) por parte de quienes llevan a cabo los escraches. El presente trabajo pretende analizar los conflictos entre esos derechos fundamentales con el fin de ofrecer unas respuestas ponderadas, las cuales concluyen con un «no» al escrache y un «sí» a la manifestación.

\section{Abstract:}

The recent practice of «escraches» in Spain, in the context of the economic crisis, has raised a complex debate about the confrontation between fundamental rights. Indeed, on one hand, it must be 
taken into account the right to free exercise of public office as well as personality rights (integrity, private and family life and peaceful enjoyment of the home) when not acting as a public representative. On the other hand, it must be taken in consideration the exercise of other fundamental rights (expression, demonstration) by those who perform escraches. This paper intends to analyze the conflicts between these fundamental rights in order to provide balanced responses, which lead to the following conclusion: «no» to escrache and «yes» to demostration.

\section{Palabras clave:}

Escrache. Representante público. Legitimidad de origen. Legitimidad de ejercicio. Derecho de manifestación. Libertad de expresión. Derecho a permanecer en el cargo público. Derecho a la vida privada y al domicilio.

\section{Key words:}

Escrache. Public representative. Legitimacy in origin. Legitimacy in exercise. Right to demonstrate. Freedom of speech. Right to remain in office. Right to privacy and to peaceful enjoyment of home. 